\title{
Annual Observations of Climatic Impacts in the Songhua River Basin, China
}

\author{
Xiaocheng Song ${ }^{1}$ and Liu Jing ${ }^{2}$ \\ ${ }^{1}$ School of Municipal and Environmental Engineering, Harbin Institute of Technology, Harbin 150090, China \\ ${ }^{2}$ State Key Laboratory of Urban Water Resource and Environment, Harbin Institute of Technology, \\ Harbin 150090, China
}

Correspondence should be addressed to Liu Jing; liujinghit0@163.com

Received 5 June 2015; Accepted 3 November 2015

Academic Editor: Christophe Cudennec

Copyright (c) 2015 X. Song and L. Jing. This is an open access article distributed under the Creative Commons Attribution License, which permits unrestricted use, distribution, and reproduction in any medium, provided the original work is properly cited.

\begin{abstract}
Heat fluxes have been recognized as determinant regarding the river effect on microclimate. The relationship between rivers and the atmosphere is particularly significant for heat fluxes and varies with the meteorology and hydrology. In this study, based on annual observation data from the Songhua River Basin (Harbin, China), a regression and a stochastic model were used to analyze the relationship of the atmosphere-river daily maximum temperatures and evaluate the heat fluxes. The root mean square error (RMSE) of the river temperature was $2.21^{\circ} \mathrm{C}$ with the regression method, improving to $0.83^{\circ} \mathrm{C}$ with the stochastic model. The net shortwave radiation flux was the dominant heat gain component, while the latent heat flux accounted for the main heat loss. The sensible heat flux represented the smallest contribution. The river thermal effect in summer mainly resulted from the latent heat exchange, while the effect of the sensible heat exchange tended to be stronger in spring and autumn.
\end{abstract}

\section{Introduction}

The rapid urbanization of large Chinese cities led to environmental impacts resultant from anthropological emissions. The urban heat island (UHI) phenomenon has obtained wide attention as a significant thermal environmental problem. In many cases, land cover changes affect the variation in the atmosphere temperatures through heat exchange processes. Previous studies found that the UHI can be mitigated with certain land cover types such as green spaces and water bodies [1-4]. Rivers within urban areas have a positive effect on their microclimate, naturally cooling the surrounding areas because of evaporation in hot conditions or heating them through heat exchange in cold conditions [5-8]. These natural processes highly depend on the meteorological conditions and physical characteristics of rivers.

The atmosphere and river temperatures play an important role in the thermal effect of rivers on the atmosphere and their relationship can be analyzed through several methods. Regression methods involve one input dataset (e.g., atmosphere temperature) and one output dataset (e.g., river temperature), while simple regression models have been successfully used in early stages $[9,10]$. Linear regression proved to be an easy and sometimes quite effective method for weekly or monthly time scales $[11,12]$. The river temperature has been shown to respond linearly to the atmosphere temperature for different time lags (days, months, seasons, and years) and regions, with better fits for increased time scales $[9,12]$. In addition, nonlinear regression models have been used on average weekly basis $[13,14]$, with the most widely used being the logistic function model proposed by Mohseni et al. [13] to analyze the weekly mean maximum and average daily temperatures $[15,16]$. However, the logistic regression performs poorly for daily data [16]. Stochastic models have often been used to analyze daily temperatures, while variable approaches have been used to model the longterm annual and short-term residual components $[17,18]$.

The abovementioned studies mainly focused on the temperature relationship. However, heat exchange processes in the atmosphere-river interface must be considered when studying energy mechanisms, to understand the reactions involved in climate changes. The thermal mitigation effect 
of rivers is mainly based on two heat exchange processes: evaporation, which depends on the atmosphere and river temperature, moisture content, and other meteorological variables, and sensible heat exchange, attributed to the temperature differences between the atmosphere and the river. The heat flux components can be calculated using meteorological data, as described in previous studies [1921]. The magnitude and importance of the river heat budget components vary depending on the spatial and seasonal conditions. The heat exchange between the river and the overlying atmosphere can either add or subtract energy from the river reaches. However, most of the above studies were limited to a hydrological perspective, mainly focusing on the atmospheric effect on rivers, predicting their temperature and heat gain and evaluating the effects on river discharge, aquatic habitats, and ecosystems. Previous studies have discussed the heat exchange in lakes [22-24], with only few dealing with the thermal regime of large rivers $[25,26]$. Previous research based on observations analyzed the thermal mitigation on the atmosphere by urban rivers in China $[27,28]$. However, these studies were performed for relatively short and discontinuous time scales or in South China, where the climate is very different from Northeast China.

Therefore, to understand the annual thermal effect of large rivers on the adjacent atmosphere in severely cold regions, we analyzed the temperature relationship and heat exchange processes between the atmosphere and rivers for different seasons. Based on long-term observation data, the annual microclimate variables for the observation sites were discussed to illustrate the meteorological characteristics of the Songhua River Basin, while models were used to explore the relationship between the atmosphere and river temperature. Finally, the heat components were calculated to analyze the seasonal river effect on the atmosphere, defined by the meteorological parameters, and their influence on the temperature.

\section{Study Site}

The observations were conducted in the Harbin section of the Songhua River in the Heilongjiang Province, Northeast China $\left(\sim 45^{\circ} 25^{\prime}-45^{\circ} 30^{\prime} \mathrm{N}, 126^{\circ} 20^{\prime}-126^{\circ} 25^{\prime} \mathrm{E}\right.$, Figure 1$)$. Harbin is a large city located in a severely Chinese cold zone, with a population of over ten million, and crossed by a large river, the Songhua. The Songhua River flows from west to east, with a large runoff of over $2000 \mathrm{~m}^{3} / \mathrm{s}$ in summer and an average width of over one kilometer. Harbin is located in the middle of the basin, with a watershed of $389769 \mathrm{~km}^{2}$.

The hydrological station, from which multiple river measurements were obtained, is shown in Figure 1. To determine the climatic conditions of the basin, meteorological data were collected from a station located near the river (Figure 1), assuming that lateral cross-estuary variations were negligible. The variables measured included the atmosphere and river temperature, relative humidity, wind speed, and solar radiation during 2013. The river temperature was measured $0.1 \mathrm{~m}$ below the river surface. River data were obtained hourly for April 15-October 23, 2013, to avoid river ice conditions (freezing-thawing). The monthly averages of the main climatic parameters are summarized in Table 1 , showing that Harbin has distinct seasonal characteristics, being cold, windy, and dry in spring, with additional freezing conditions in autumn, and humid with concentrated rainfall in summer. The monthly difference between the maximum and minimum atmospheric temperature was much higher than for the river, especially in spring and autumn.

\section{Methodology}

3.1. Temperature Relationships between the River and the Atmosphere. Regression models have been used to examine the relationship between the atmospheric and river temperature using only one of them and including mostly weekly and monthly data. First, the relationships between the atmosphere and river temperatures were investigated using a linear logistic function [13] for the daily maximum and weekly mean maximum temperatures:

$$
T_{w}=\mu+\frac{\alpha-\mu}{1+e^{\varphi\left(\beta-T_{a}\right)}},
$$

where $T_{w}$ is the estimated river temperature $\left({ }^{\circ} \mathrm{C}\right), T_{a}$ the measured atmospheric temperature $\left({ }^{\circ} \mathrm{C}\right), \mu$ the estimated minimum river temperature, $\alpha$ the estimated maximum stream temperature, $\beta$ the atmospheric temperature at the inflection point of the function, and $\varphi$ a measure of the steepest function slope.

Since regression methods could only show simple relationships, we also used a stochastic model [17] to search for further daily relations. This model separated the timedependent temperatures $T(t)$ in two different components: the annual long-term component $T A(t)$ and the short-term residuals $R(t)$ as follows:

$$
T(t)=T A(t)+R(t),
$$

where $t$ is the Julian day number; for example, January 1 is day 1 and December 31 is day 365.

The annual component of the river and atmosphere can be represented by a Fourier series analysis [17] or a sine function of the time-series [18]. In the present study, a sine function was used, given its simplicity and good accuracy [15]:

$$
T A(t)=a+b \sin \left(\frac{2 \pi}{365}\left(t+t_{0}\right)\right),
$$

where $T A(t)$ is the long-term component of a temperature time-series $\left({ }^{\circ} \mathrm{C}\right)$ and $a, b$, and $t_{0}$ are the fitted coefficients.

To model the residuals, the second-order Markov process was used [18]. The residual component of the river and atmosphere can be obtained by subtracting the actual temperature from the annual components. There are several approaches to model the residual time-series, each with its own characteristics [15]. Previous studies showed a comparatively good performance and simplicity for the second-order Markov model [15]. Therefore, the residuals time-series was used to calibrate it:

$$
R_{w}(t)=A_{1} R_{w}(t-1)+A_{2} R_{w}(t-2)+K R_{a}(t),
$$




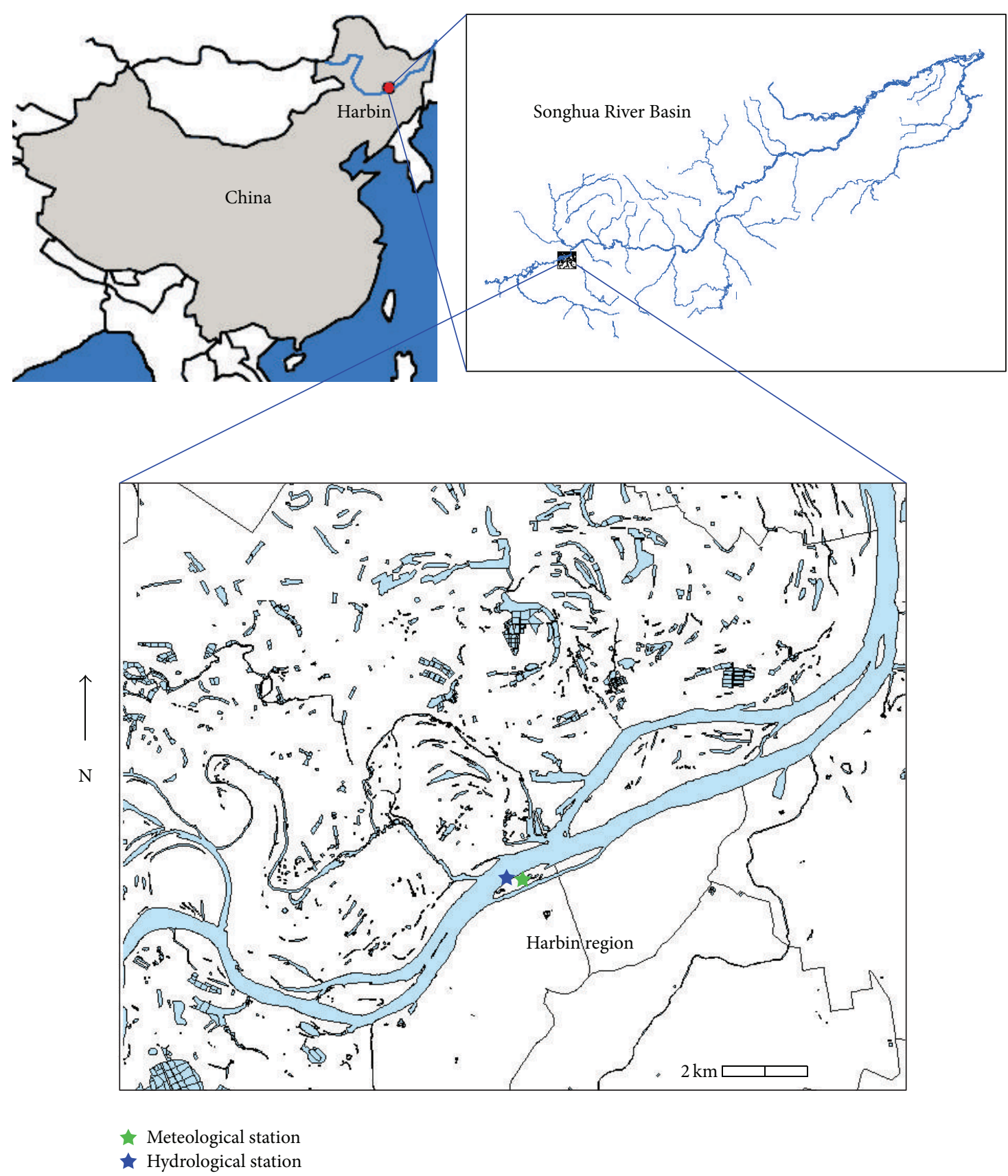

FIGURE 1: Map of the study area, with the green and blue stars showing the position of the meteorological and hydrological observation sites.

where $R_{w}(t), R_{w}(t-1)$, and $R_{w}(t-2)$ are the residuals of the river temperature at times $t, t-1$, and $t-2$, respectively, $R_{a}(t)$ is the residual of the atmospheric temperature at time $t, A_{1}$ and $A_{2}$ are autoregressive coefficients, calculated by autocorrelation coefficients for a lag of 1 and 2 days, and $K$ is a regression coefficient reflecting the heat exchange between the river and atmosphere temperature.

3.2. River-Atmosphere Relationship on the Heat Flux. The heat budget for the atmosphere-river interface is one of the most important elements to understand the influence of urban rivers on a city's thermal climate. For a relatively small spatial and short time scale, it can be assumed, for urban rivers, that the changes in temperature along the river are small compared to the temporal changes, once the river reaches a uniform temperature [29]. The main components of the heat flux are the net radiation (including the net shortwave and longwave radiation) and the latent, sensible, and conductive heat fluxes in the river underlayer. Although other components can be considered, such as the river bed heat flux, their contribution is generally small compared to the above components [19]. If we mainly consider the river surface and use the energy balance of the heat processes at the surface, the heat gain should equal the heat loss, with a total 
TABLE 1: Monthly averages of the main climatic parameters.

\begin{tabular}{|c|c|c|c|c|c|c|c|c|c|c|}
\hline \multirow[t]{2}{*}{ Month } & \multicolumn{3}{|c|}{$\begin{array}{c}\text { River temperature } \\
\left({ }^{\circ} \mathrm{C}\right)\end{array}$} & \multicolumn{3}{|c|}{$\begin{array}{c}\text { Atmosphere temperature } \\
\left({ }^{\circ} \mathrm{C}\right)\end{array}$} & \multirow{2}{*}{$\begin{array}{l}\text { Relative } \\
\text { humidity } \\
(\%)\end{array}$} & \multirow{2}{*}{$\begin{array}{l}\text { Wind } \\
\text { velocity } \\
(\mathrm{m} / \mathrm{s})\end{array}$} & \multirow{2}{*}{$\begin{array}{c}\text { Solar } \\
\text { radiation } \\
\left(\mathrm{W} / \mathrm{m}^{2}\right)\end{array}$} & \multirow[t]{2}{*}{ Runoff $\left(\mathrm{m}^{3} / \mathrm{s}\right)$} \\
\hline & Max. & Ave. & Min. & Max. & Ave. & Min. & & & & \\
\hline April & 9.92 & 9.39 & 9.01 & 19.27 & 12.82 & 5.57 & 38.55 & 3.09 & 254.67 & 1302.60 \\
\hline May & 12.53 & 11.97 & 11.56 & 14.75 & 11.09 & 6.93 & 65.78 & 3.59 & 143.33 & 702.93 \\
\hline June & 23.99 & 23.51 & 23.23 & 26.86 & 22.34 & 17.66 & 64.68 & 2.60 & 275.81 & 2389.98 \\
\hline July & 25.09 & 24.75 & 24.5 & 26.94 & 23.11 & 18.75 & 72.55 & 2.56 & 217.24 & 3992.76 \\
\hline August & 25.21 & 24.84 & 24.59 & 26.65 & 21.92 & 17.91 & 74.04 & 1.87 & 218.71 & 2962.94 \\
\hline September & 20.11 & 19.75 & 19.45 & 21.27 & 15.41 & 10.03 & 67.08 & 2.21 & 183.08 & 2832.21 \\
\hline October & 10.75 & 10.42 & 10.20 & 13.67 & 7.63 & 1.14 & 51.42 & 2.82 & 136.62 & 793.05 \\
\hline Average & 18.23 & 17.80 & 17.51 & 21.34 & 16.33 & 11.14 & 62.01 & 2.68 & 204.21 & 2139.50 \\
\hline
\end{tabular}

heat at the surface of zero. Therefore, the heat budget for the atmosphere-river interface can be expressed as follows [30]:

$$
\begin{aligned}
H_{S}+H_{L} & =R_{\text {net }}, \\
R_{\text {net }}+H_{C}+H_{E}+H_{G} & =0, \\
H_{S} & =(1-\alpha) S_{R} \downarrow, \\
H_{L} & =\varepsilon L_{R} \downarrow-\varepsilon \sigma T_{w}^{4} \\
& =\varepsilon \sigma T_{a}^{4}-\varepsilon \sigma T_{w}^{4},
\end{aligned}
$$

where $H_{S}$ is the net shortwave radiation $\left(\mathrm{W} / \mathrm{m}^{2}\right), H_{L}$ is the net longwave radiation $\left(\mathrm{W} / \mathrm{m}^{2}\right), R_{\text {net }}$ is the net solar radiation $\left(\mathrm{W} / \mathrm{m}^{2}\right), H_{C}$ and $H_{E}$ are the sensible and latent heat fluxes at the atmosphere-river interface $\left(\mathrm{W} / \mathrm{m}^{2}\right)$, respectively, $H_{G}$ is the heat conduction flux from the river surface to the inner river body $\left(\mathrm{W} / \mathrm{m}^{2}\right), S_{R} \downarrow$ is the downward shortwave radiation to the river surface through the atmosphere $\left(\mathrm{W} / \mathrm{m}^{2}\right), L_{R} \downarrow$ is the downward longwave solar radiation from the atmosphere $\left(\mathrm{W} / \mathrm{m}^{2}\right), \sigma$ is the Stefan-Boltzmann constant $\left(5.67 \times 10^{-8} \mathrm{~W} / \mathrm{m}^{2} \mathrm{~K}^{4}\right), \sigma T_{w}^{4}$ is the upward longwave solar radiation $\left(\mathrm{W} / \mathrm{m}^{2}\right), T_{w}$ and $T_{a}$ are the absolute temperature of the atmosphere and river surface $(\mathrm{K})$, and $\alpha$ and $\varepsilon$ are the surface shortwave reflection and radiation coefficients, assumed as 0.07 and 0.96 , respectively, and relevant to the surface state and solar height angle.

One of the main components of the heat fluxes and perhaps the most difficult to estimate is the evaporation from the river surface. Evaporation represents the primary river heat loss, with an associated increase in the atmospheric humidity. Various methods to deal with the evaporation have been proposed for lakes [31] and rivers [32]. The easiest and most widely used method is the mass transfer method, proposed by Harbeck et al. [33]. Since then, many methods were developed including more variables and fits for different time scales [30, 34, 35]. A comparison of these methods for different areas showed that the Penman method [30] provided relatively good results for daily estimations [26, 31]. Once the evaporation rate was estimated (9), the latent heat became a function of the atmospheric temperature and its flux could be calculated by (11) [19]:

$$
\begin{aligned}
E= & \frac{s}{s+\gamma} \frac{R_{\text {net }}}{L \rho} \times 86.4 \\
& +\frac{\gamma}{s+\gamma}(0.26(0.5+0.54 V))\left(e_{s}-e_{a}\right), \\
H_{E}= & E L \rho \\
L= & 2454.9-2.366 T_{a},
\end{aligned}
$$

where $E$ is the evaporation rate ( $\mathrm{mm} /$ day), $L$ the latent heat of the river vaporization $(\mathrm{J} / \mathrm{kg}), \rho$ the density of the river water $\left(\mathrm{kg} / \mathrm{m}^{3}\right), s$ the slope of the saturated vapor pressuretemperature curve $\left(\mathrm{Pa} /{ }^{\circ} \mathrm{C}\right), \gamma$ the psychometric constant $\left(\mathrm{Pa} /{ }^{\circ} \mathrm{C}\right), V$ the wind velocity $2 \mathrm{~m}$ above the river surface $(\mathrm{m} / \mathrm{s})$, $e_{s}$ the saturated vapor pressure at atmospheric temperature $(\mathrm{mb})$, and $e_{a}$ the vapor pressure calculated for the atmospheric temperature and corresponding relative humidity (mb).

The sensible heat refers to the difference between the river and atmosphere temperature and is usually affected by atmospheric turbulent conditions, such as the pressure and wind velocity. The expression used in this study was as follows [26]:

$$
H_{C}=2.32 V \frac{P_{a}}{1000}\left(T_{a}-T_{w}\right),
$$

where $P_{a}$ is the atmospheric pressure $(\mathrm{mmHg})$.

In heat balance calculation (6), the heat gain of the river surface was positive, while the heat loss was negative. Therefore, the net shortwave radiation was always positive. The latent heat flux represents an energy loss, with $H_{E}$ usually becoming negative. The sensible heat flux depends on the temperature difference and can be positive or negative. The conductive heat flux into the river was calculated by the other components. If heat was conducted from the surface to the river underlayer, the conductive heat flux was negative, or vice versa. 


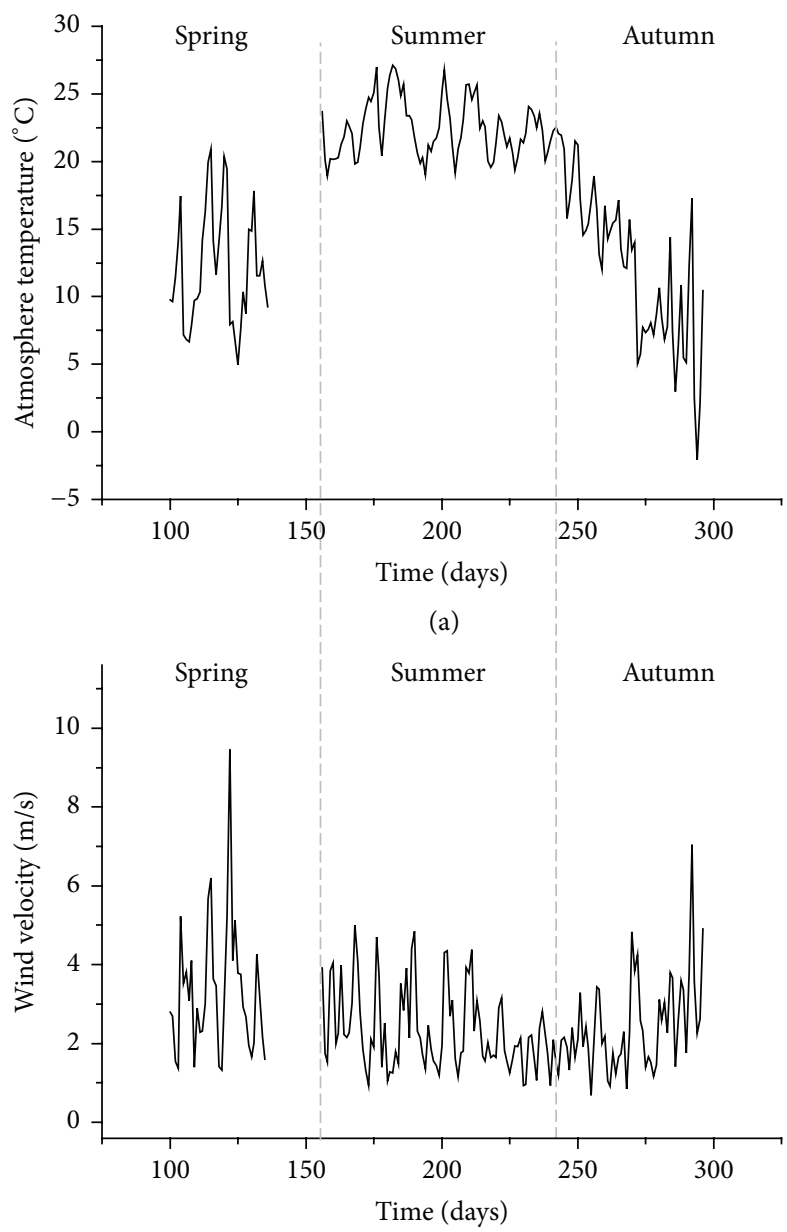

(c)

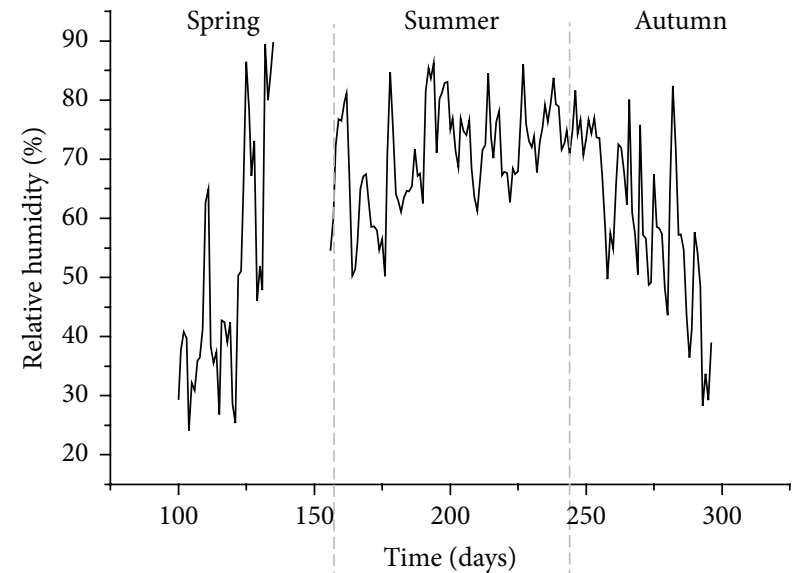

(b)

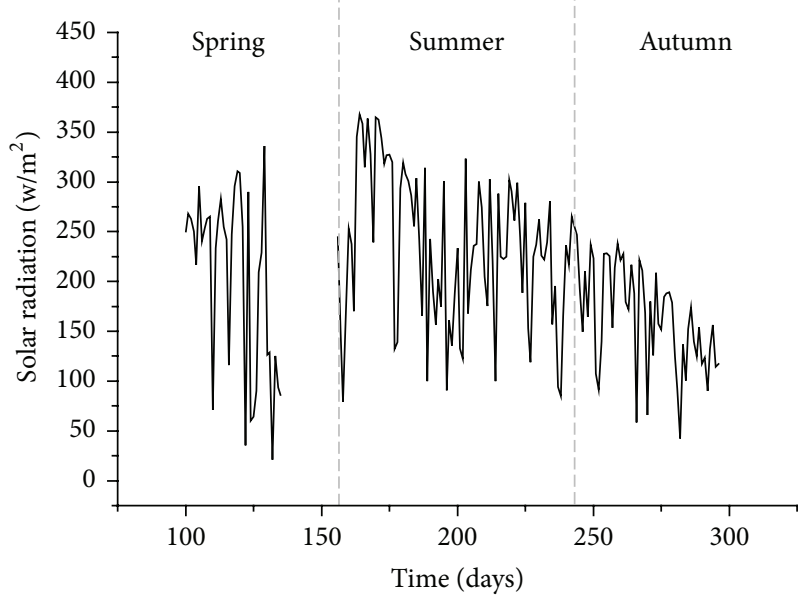

(d)

FIgURE 2: Daily average atmospheric temperature (a), relative humidity (b), wind velocity (c), and solar radiation (d).

\section{Results and Discussion}

\subsection{Time Variation of Typical Meteorological and Hydrological Variables}

4.1.1. Meteorological Variables. As shown in Figure 2, there was a gap in the surface data in spring due to equipment maintenance, during which no data was collected. To illustrate the annual seasonal change, the measured data was grouped in three seasons based on temperature: spring (April-May, days 91-151), summer (June-August, days 152243), and autumn (September-October, days 244-304).

All variables showed the same seasonal trend with higher values in summer and lower in spring and autumn, except for the wind velocity, which showed a relatively opposite pattern (Figure 2). The maximum atmosphere temperature $\left(27.13^{\circ} \mathrm{C}\right)$ occurred on July 1 and the minimum $\left(-2.06^{\circ} \mathrm{C}\right)$ on October 21 (Figure 2(a)). The average seasonal temperatures in spring, summer, and autumn were $11.95,22.46$, and $11.52^{\circ} \mathrm{C}$, respectively. The maximum temperature differences between two consecutive days in spring $\left(10.26^{\circ} \mathrm{C}\right)$ and autumn $\left(14.78^{\circ} \mathrm{C}\right)$ were much larger than in summer $\left(4.44^{\circ} \mathrm{C}\right)$, indicating unstable atmospheric conditions in spring and autumn and relative stability in summer.

The relative humidity time-series showed a consistent pattern with seasonal variability (Figure 2(b)). The mean seasonal values varied from $52.16 \%$ in spring to $70.42 \%$ in summer, with a dramatic rise in spring.

The wind velocity showed a different pattern (Figure 2(c)), being lower in late summer and early autumn and higher in spring and late autumn, with the highest value $(9.47 \mathrm{~m} / \mathrm{s})$ observed on May 2.

The solar radiation also showed a seasonal trend but did not vary smoothly throughout the year (Figure 2(d)). The highest solar radiation $\left(356.56 \mathrm{~W} / \mathrm{m}^{2}\right)$ occurred in midJune, after which it gradually declined. The summer average $\left(159.85 \mathrm{~W} / \mathrm{m}^{2}\right)$ was lower than in spring $\left(199.00 \mathrm{~W} / \mathrm{m}^{2}\right)$ and summer $\left(237.25 \mathrm{~W} / \mathrm{m}^{2}\right)$. The largest difference between two consecutive days occurred in spring $\left(254.40 \mathrm{~W} / \mathrm{m}^{2}\right)$, followed by summer $\left(214.12 \mathrm{~W} / \mathrm{m}^{2}\right)$ and autumn $\left(162.85 \mathrm{~W} / \mathrm{m}^{2}\right)$, which is related to the seasonal weather conditions and especially the cloud cover. 


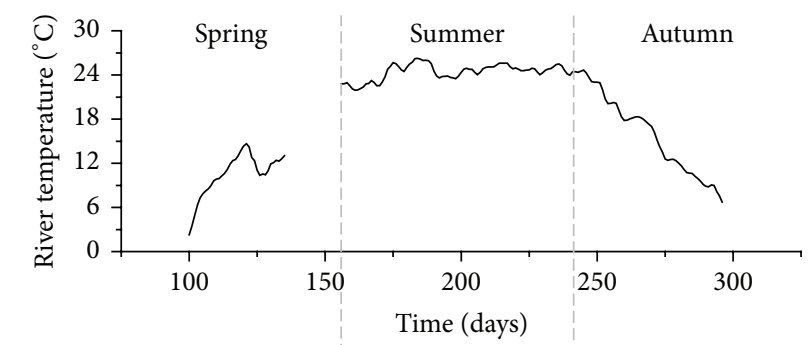

(a)

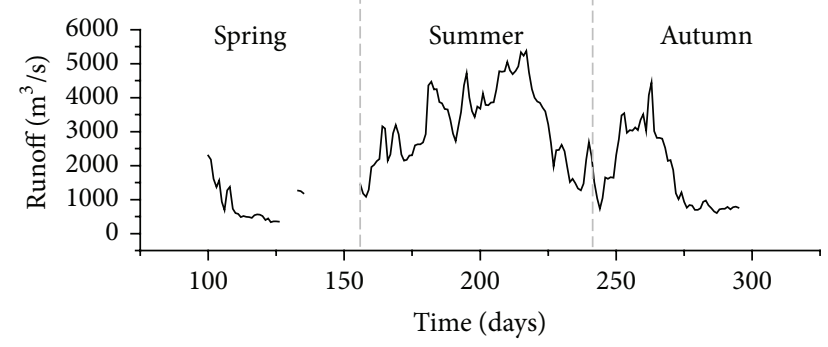

(b)

FIGURE 3: Daily average river temperature (a) and runoff (b).

4.1.2. Hydrological Variables. Compared with the atmospheric temperature variation (Figure 2(a)), the surface river temperature showed a much smoother annual trend (Figure 3(a)). Its maximum daily range (maximum difference between the daily maximum and minimum) was 1.50, 1.04, and $1.28^{\circ} \mathrm{C}$ in spring, summer, and autumn, respectively. The values increased from 2.61 to $22.82^{\circ} \mathrm{C}$ in spring with a slightly reversed trend in May, while, in summer, they were relatively stable, with an average of $24.37^{\circ} \mathrm{C}$. The river temperature slope largely decreased in autumn from 24.23 to $6.74^{\circ} \mathrm{C}$. Compared with Figure 2(a), this variation was consistently stable with some seasonal dependency. The maximum temperature difference between two consecutive days was relatively smaller in summer, mainly because of the large heat capacity, runoff, and heat exchange of the river, which are responsible for its thermal mitigation properties in the adjacent environment especially during hot summers.

The annual average runoff of the Songhua River in Harbin was $1976.88 \mathrm{~m}^{3} / \mathrm{s}$ (Figure 3(b)), with a large peak in summer. The maximum and minimum daily averages were $5374.79 \mathrm{~m}^{3} / \mathrm{s}$ on August 5 and $336.04 \mathrm{~m}^{3} / \mathrm{s}$ on May 3. The runoff in summer $\left(3115.23 \mathrm{~m}^{3} / \mathrm{s}\right)$ was almost threefold the early spring flow $\left(1002.77 \mathrm{~m}^{3} / \mathrm{s}\right)$ and twofold the late autumn one $\left(1812.63 \mathrm{~m}^{3} / \mathrm{s}\right)$, which is attributed to the large rainfall in summer and drought since late autumn, with the former incrementing and the latter decreasing the runoff.

4.2. Relevance of the River and Atmospheric Temperature. The daily maximum temperature acts as a signal of the diurnal river activity and weather conditions, with a more likely atmosphere-river interaction for intenser thermal regimes. Therefore, the daily maximum values were used to analyze the relationship between the atmosphere and river temperatures.

Since different models were used to study the relationship between the atmosphere and river temperatures, the root mean square error (RMSE) was used to compare their relative performance [36]:

$$
\text { RMSE }=\sqrt{\frac{\sum_{i=1}^{N}\left(T_{\text {sim }}-T_{\mathrm{obs}}\right)^{2}}{N-2}},
$$

where $T_{\text {sim }}$ is the maximum simulated river temperature $\left({ }^{\circ} \mathrm{C}\right)$, $T_{\text {obs }}$ the maximum observed river temperature $\left({ }^{\circ} \mathrm{C}\right)$, and $N$ the number of daily river temperature observations.

4.2.1. Regression Models. To evaluate the relationship between the atmosphere and river temperature by regression analysis, both the linear and logistic functions were applied to daily and weekly data. The daily maximum temperature showed a significant scatter and the RMSE of the linear regression was $4.94^{\circ} \mathrm{C}$ (Figure $4(\mathrm{a})$ ). The data were plotted according to the seasons, with better correlations as the time scale increased to weeks (Figure 4(b)) and the RMSE decreased to $2.43^{\circ} \mathrm{C}$. The logistic regression function was fitted to the weekly data, showing good agreement (Figure $4(\mathrm{c})$ ). The following logistic equation was calculated:

$$
T_{W}=\frac{27.53}{1+e^{0.21\left(16.95-T_{a}\right)}} .
$$

The logistic model for the daily maximum temperature on a weekly average basis was better than the regression model, with an overall RMSE of $2.21^{\circ} \mathrm{C}$.

4.2.2. Stochastic Models. Since a time scale of weeks is not precise for microclimate studies, a stochastic model was used for a daily analysis of the interactions in the temperature time-series. The annual components of the maximum temperature were regressed using (3) to obtain the following equations:

$$
\begin{aligned}
& T A_{a}(t)=14.81+12.98 \sin \left(\frac{2 \pi}{365}(t-105.4)\right) \\
& T A_{w}(t)=9.57+16.88 \sin \left(\frac{2 \pi}{365}(t-112.6)\right),
\end{aligned}
$$

where $T A_{a}(t)$ and $T A_{w}(t)$ are the long-term components of the atmosphere and river temperature $\left({ }^{\circ} \mathrm{C}\right)$, respectively.

The atmosphere and river temperatures had similar trends for all seasons (Figure 5), even though their maximums were different and occurred in different days. The long-term component of atmospheric temperature peaked on July 16 (day 197) with a value of $27.89^{\circ} \mathrm{C}$, while the river temperature peaked on July 23 (day 204) reaching $26.45^{\circ} \mathrm{C}$. The maximum river temperature revealed a six-day hysteresis in relation to the atmosphere because of the river's large thermal capacity. The daily atmospheric temperature residuals varied more compared to the river.

The residual component was obtained by removing the annual component from the actual temperature. The resulting time-series was analyzed to link the atmospheric and river temperatures. The river residuals were calculated as follows:

$$
R_{w}(t)=0.92 R_{w}(t-1)-0.39 R_{w}(t-2)+0.12 R_{a}(t) .
$$

The optimised $K$ for the present study was 0.12 . 


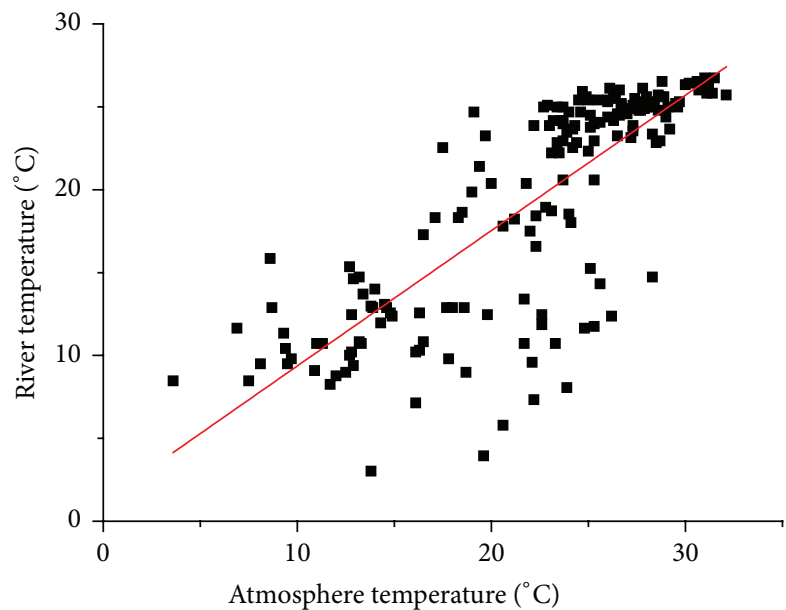

(a)

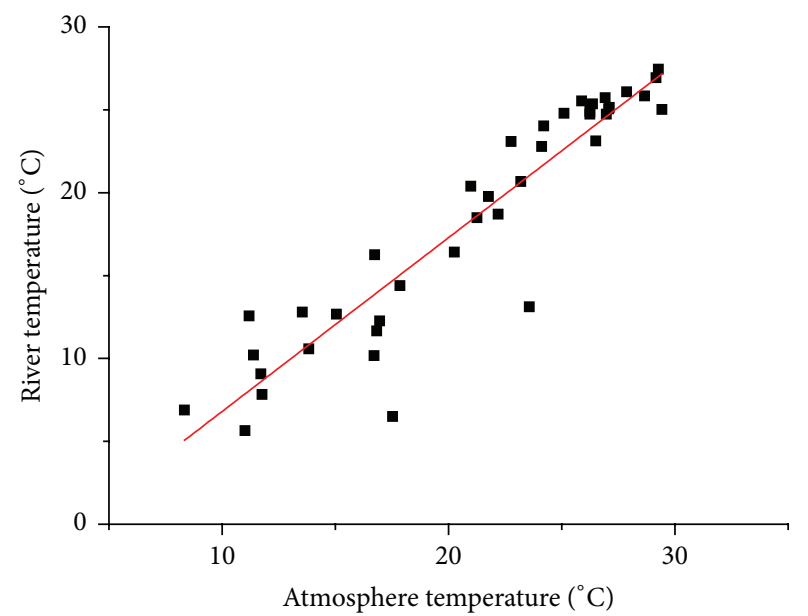

(b)

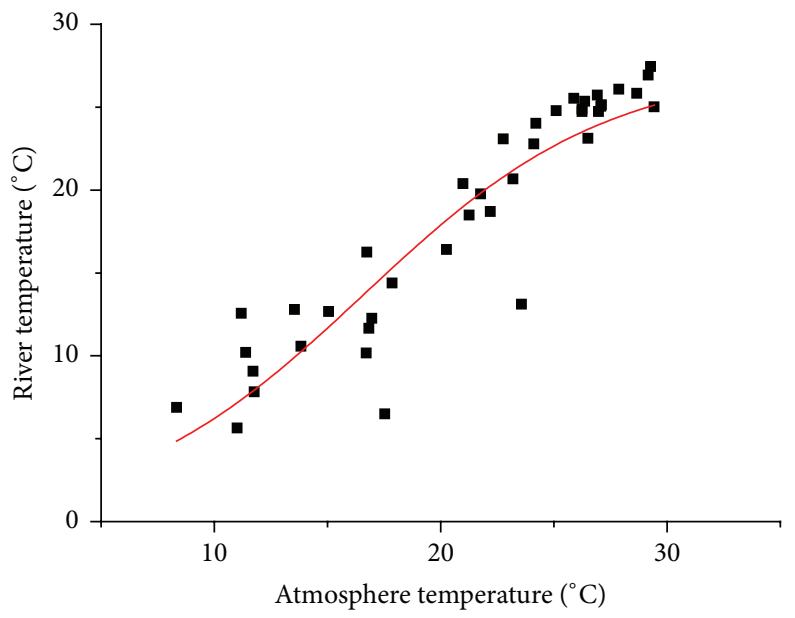

(c)

FIGURE 4: Relationship between the weekly mean river and atmosphere temperatures. The line indicates the fitted regression model.

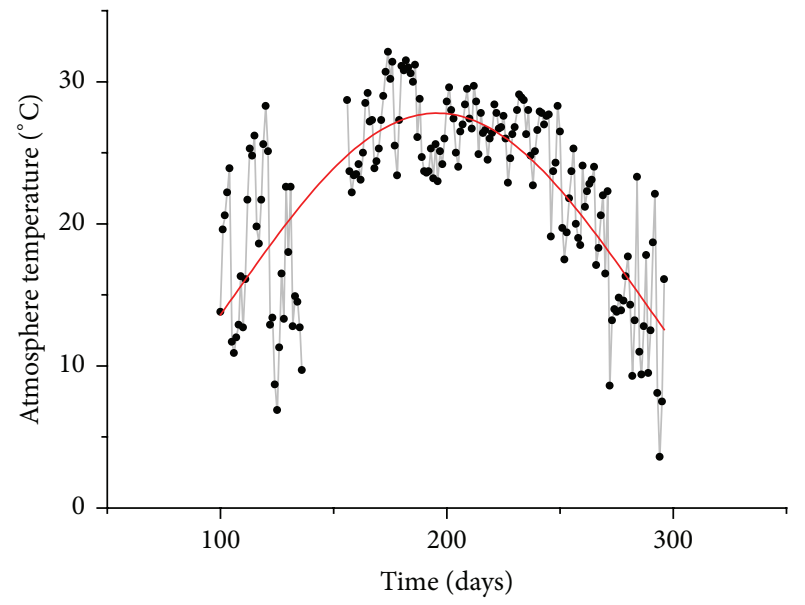

(a)

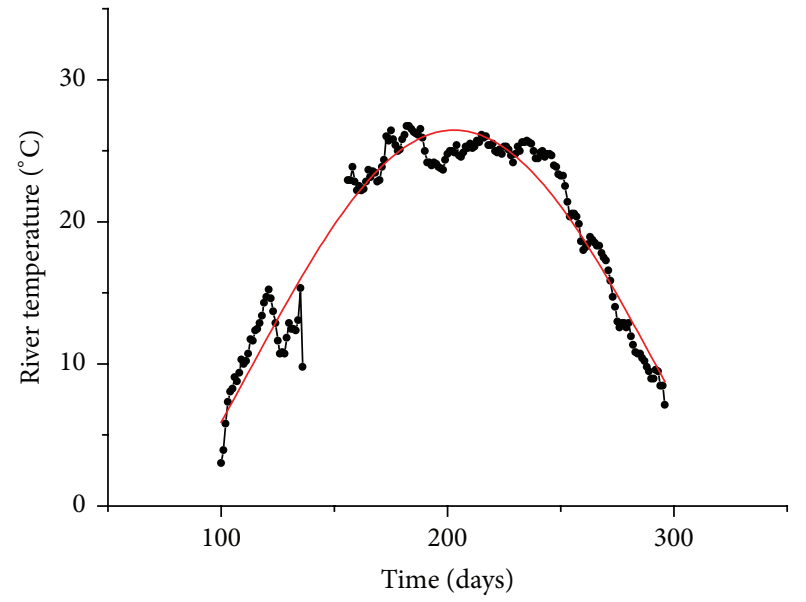

(b)

FIGURE 5: Daily maximum temperatures of the atmosphere (a) and river (b). The red line indicates the fitted sine regression model. 


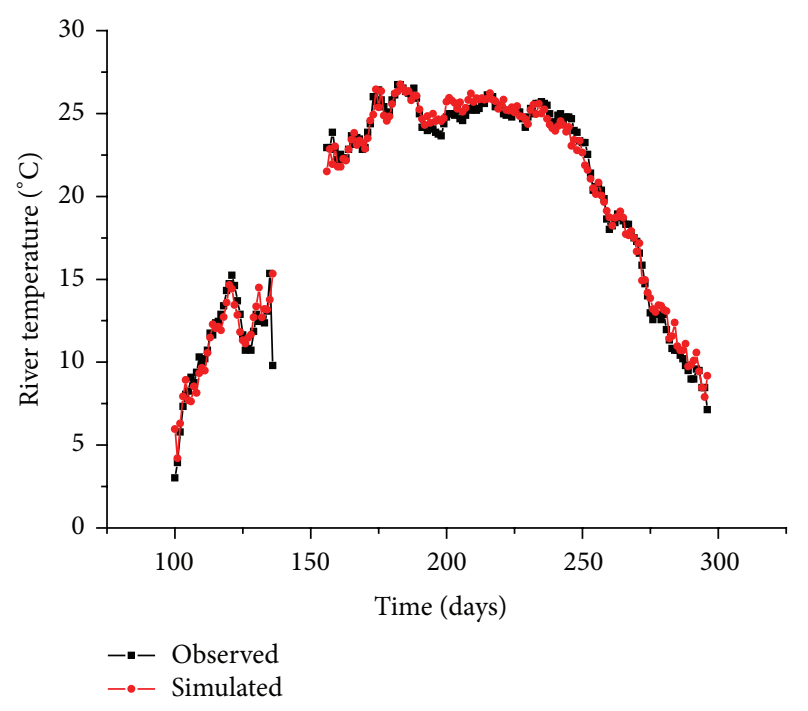

FIGURE 6: Observed and simulated daily maximum river temperatures.

Combining (2) with (15)-(16), the daily maximum river temperatures were calculated, with a good agreement between simulated and observed values and a RMSE of $0.83^{\circ} \mathrm{C}$. The simulated and observed temperatures were very close during most seasons (Figure 6) and especially in summer. However, the maximum temperatures were slightly underestimated in spring and slightly overestimated in late autumn.

\subsection{Heat Fluxes at the River-Atmosphere Interface}

4.3.1. Evaporation in the River. The river evaporation and corresponding fluxes were calculated with (9)-(11). The daily and monthly average evaporation rates are shown in Figure 7 and determine the latent heat flux between the atmosphere and the river and the capability of moistening the adjacent environment. The rates ranged $-6.67 \sim+14.96 \mathrm{~mm} / \mathrm{d}$ and averaged $4.28 \mathrm{~mm} / \mathrm{d}$. The maximum rates were reached in April, with a decline in the main trend in the following months (Figure $7(\mathrm{~b})$ ). The atmosphere was relatively dry in spring leading to a higher moisture transfer and meaning that the humidifying effect of the river was stronger.

Negative evaporation rates (condensation) mostly occurred in spring and autumn, when the atmospheric temperature changes were more rapid than for the river surface (Figures 2(a) and 3(a)). Because of atmospheric instability, frequent transitions in the temperature and vapor pressure are common over the river during spring and autumn, while, due to its large heat capacity, the river itself remains relatively stable. A combination of high humidity and relatively high river temperature with low wind speed and near-freezing atmospheric temperatures favored condensation over evaporation.

4.3.2. Net Radiation Components. As shown in (5)-(6), the heat flux at the atmosphere-river interface results from an energy exchange through solar radiation (net shortwave radiation), net longwave radiation, latent heat flux, and sensible heat flux. The net radiation represented the main input to the energy balance at the interface. Figure 8 shows the daily and monthly variations in the net radiation.

The net shortwave radiation fluctuated daily (Figure 8(a)) indicating variable cloud conditions and ranged 20.21$356.56 \mathrm{~W} / \mathrm{m}^{2}$, with an average of $183.82 \mathrm{~W} / \mathrm{m}^{2}$ and a maximum on June 13 . On a monthly basis (Figure $8(\mathrm{~b})$ ), it was highest in June and lowest in October.

The daily average net longwave radiation was mostly negative (Figure $8(\mathrm{a})$ ), as the outgoing longwave radiation (from the river) was mostly larger than the incoming (from the atmosphere), owing to the lower daily average atmosphere temperatures compared to the river. The monthly average net longwave radiation was always negative except in April (Figure 8(b)).

The net radiation includes the integrated net shortwave and longwave radiation, with the net shortwave radiation representing the main heat gain. The averages were mostly positive in spring and summer (Figure 8(a)) and negative in autumn. The monthly average net radiation was always positive, except in September, because of the large negative net longwave radiation values (Figure $8(\mathrm{~b})$ ). The lowest positive net radiation occurred in August, when the internal river temperature remained low and stable compared to the atmosphere.

4.3.3. Energy Budget Components. The energy budget for the atmosphere-river interface can be divided into four components: the net radiation and the sensible, latent, and conductive heat. Figure 9 shows the dynamic energy budget for the river-atmosphere interface according to (5)-(12). The incoming and outgoing energy fluxes are shown in Figure 9. The daily averages and percentage contributions of the seasonal heat flux gains and losses are shown in Table 2. The plus sign represents heat gain to the river surface and the minus sign represents heat loss.

The net radiation ranged between $-386.13 \mathrm{~W} / \mathrm{m}^{2}$ on September 29 and $737.01 \mathrm{~W} / \mathrm{m}^{2}$ on April 24 (Figure 9(a)). As the most important source of heat to the river, it accounted, on average, for more than $86 \%$ of the total heat gain in spring and summer (Table 2), mainly due to the net shortwave radiation (Figure 8). On the other hand, for the reasons mentioned above, the net radiation constituted over $46 \%$ of the total heat losses in autumn and only $7 \%$ in spring and summer.

The latent heat flux from the river surface occurred almost daily, varying between months (Figure 9(a)). The maximum daily loss $\left(-635.21 \mathrm{~W} / \mathrm{m}^{2}\right)$ occurred on April 25 , while the maximum daily gain $\left(201.08 \mathrm{~W} / \mathrm{m}^{2}\right)$ occurred on September 3. According to (9), the latent heat flux varied with the weather conditions, increasing with high wind velocity and low humidity (Figure 2). The contribution of evaporation to the heat loss was highest in April and June and lowest in September and October (Figure 9(b)). In terms of percentage (Table 2), the average daily heat losses from evaporation represented 64,75 , and $35 \%$ in spring, summer, and autumn, respectively. The large proportion in summer indicates the moistening capacity of the river, resulting in a higher relative 


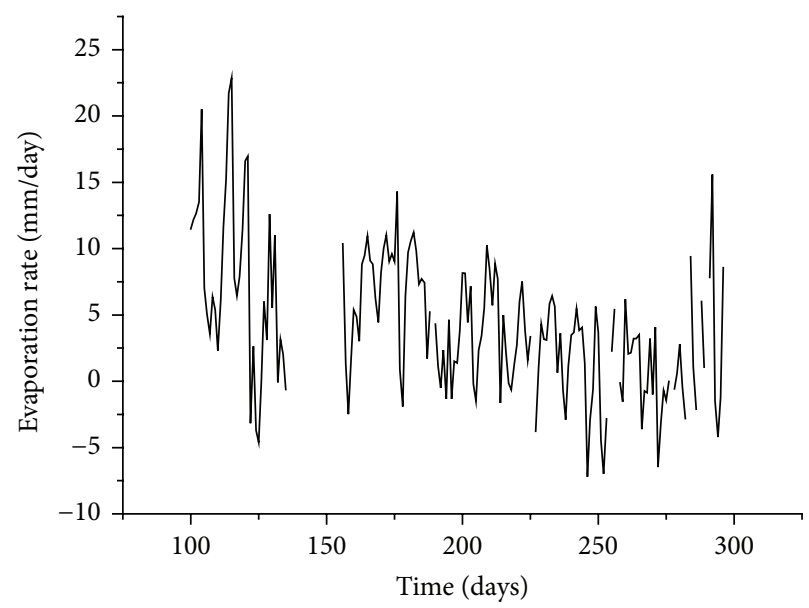

(a)

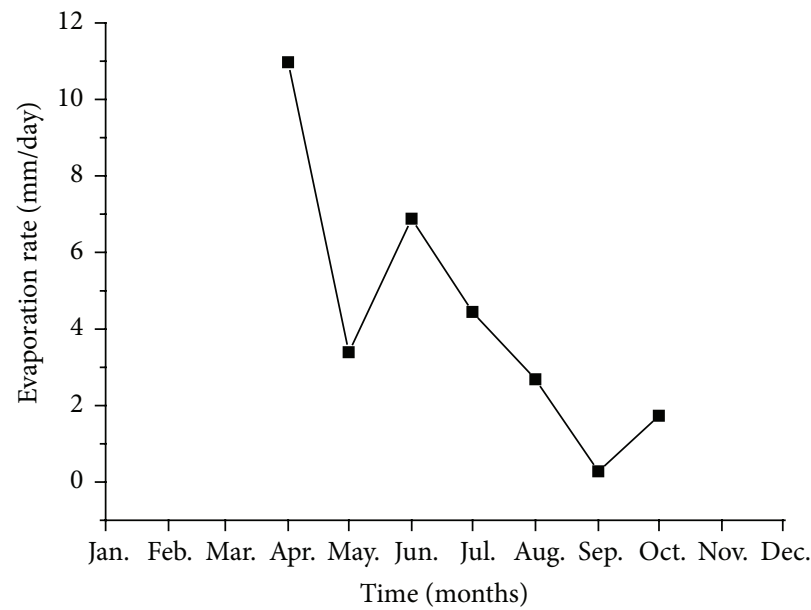

(b)

FIgURE 7: Daily and monthly average evaporation rates.

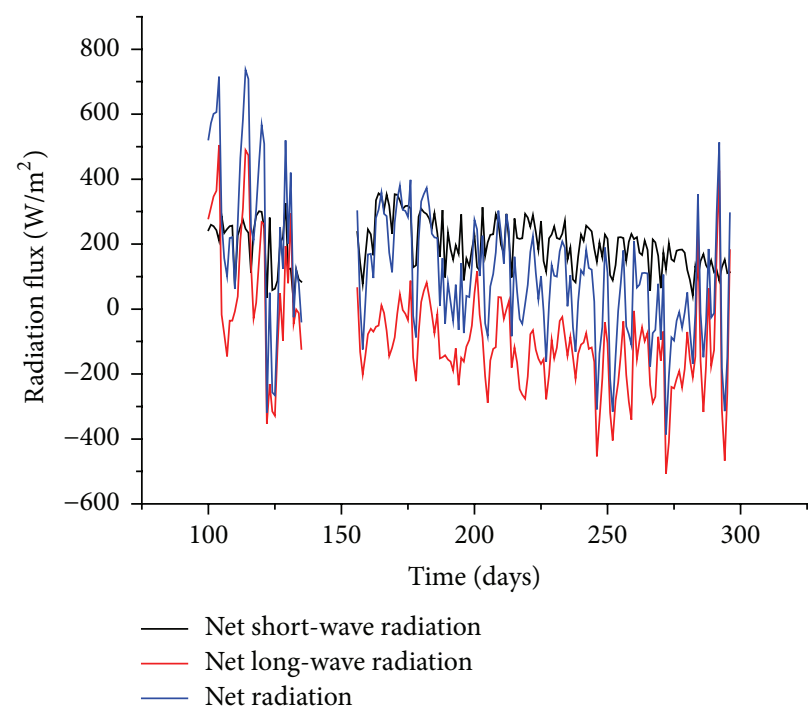

(a)

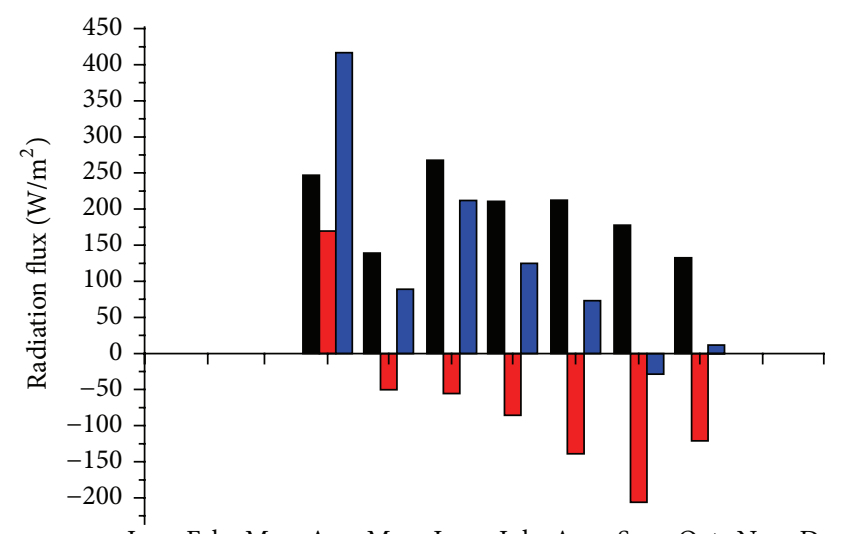

Jan. Feb. Mar. Apr. May. Jun. Jul. Aug. Sep. Oct. Nov. Dec. Time (months)
Net short-wave radiation
Net long-wave radiation
$\square$ Net radiation

(b)

FIGURE 8: Daily (a) and monthly (b) average net shortwave radiation, net longwave radiation, and net radiation.

TABLE 2: Daily averages of the seasonal heat flux gains $(+)$ and losses $(-)$. The values in bold indicate the percentage contribution of each flux component.

\begin{tabular}{|c|c|c|c|c|c|c|c|c|}
\hline \multirow{2}{*}{ Seasons } & \multicolumn{2}{|c|}{ Net radiation flux } & \multicolumn{2}{|c|}{ Latent heat flux } & \multicolumn{2}{|c|}{ Sensible heat flux } & \multicolumn{2}{|c|}{ Conductive heat flux to river } \\
\hline & + & - & + & - & + & - & + & - \\
\hline Spring $\left(\mathrm{W} / \mathrm{m}^{2}\right)$ & 314.88 & 26.92 & 9.82 & 234.40 & 15.99 & 8.69 & 25.41 & 96.09 \\
\hline Percentage contribution (\%) & 86.01 & 7.35 & 2.68 & 64.03 & 4.37 & 2.37 & 6.94 & 26.25 \\
\hline Summer $\left(\mathrm{W} / \mathrm{m}^{2}\right)$ & 146.58 & 12.61 & 6.1 & 133.39 & 0.62 & 7.77 & 15.45 & 14.98 \\
\hline Percentage contribution (\%) & 86.87 & 7.47 & 3.61 & 79.04 & 0.37 & 4.61 & 9.15 & 8.88 \\
\hline $\operatorname{Autumn}\left(\mathrm{W} / \mathrm{m}^{2}\right)$ & 62.80 & 74.2 & 31.02 & 56.71 & 3.60 & 16.37 & 62.46 & 12.61 \\
\hline Percentage contribution (\%) & 39.28 & 46.41 & 19.40 & 35.47 & 2.25 & 10.24 & 39.07 & 7.89 \\
\hline
\end{tabular}




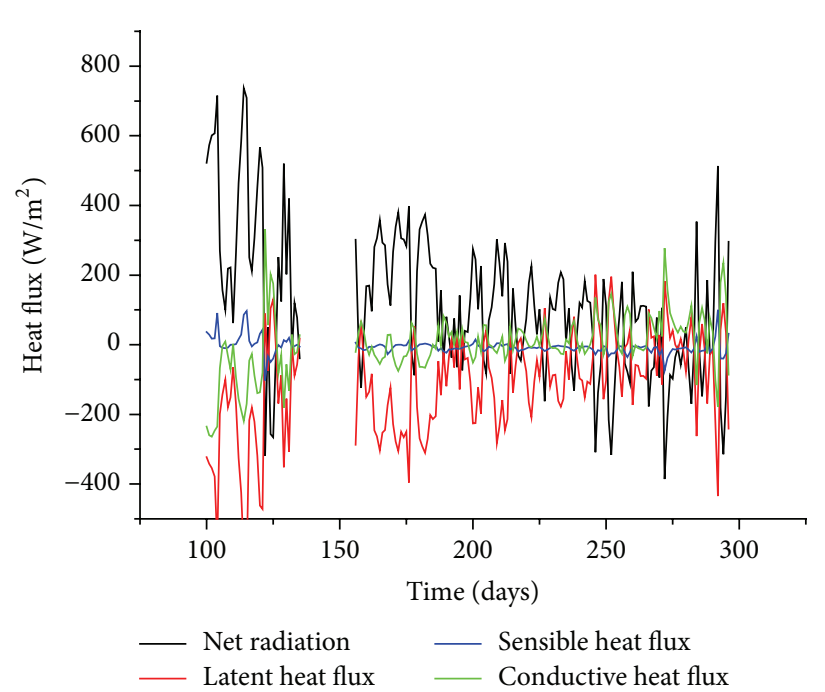

(a)

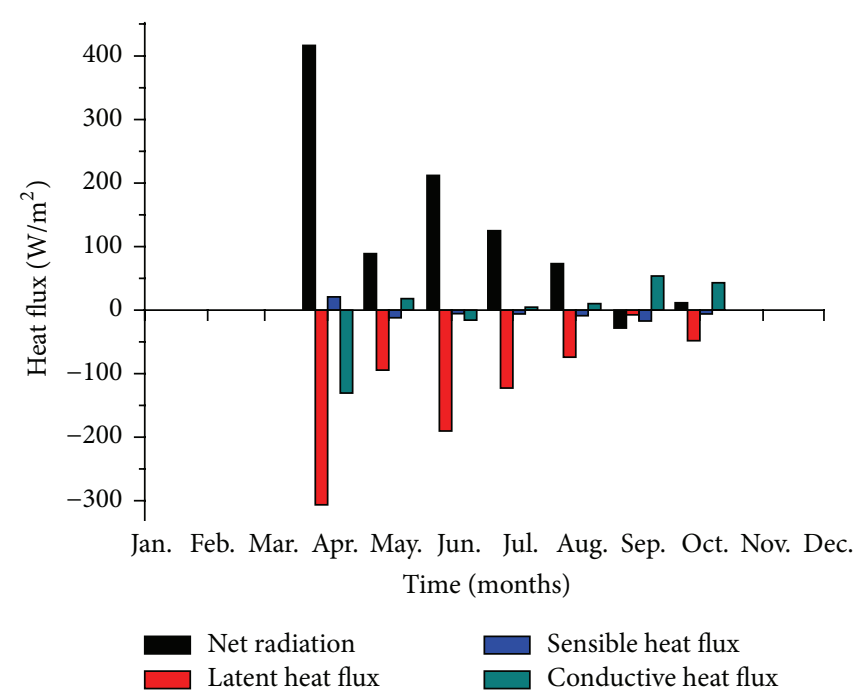

(b)

FIGURE 9: Daily (a) and monthly (b) averages for each heat flux component.

humidity in summer on the adjacent thermal environment (Figure 2(b)). Heat gain due to the latent heat flux had contributions of $2.68,3.61$, and $19.4 \%$ in spring, summer, and autumn, respectively, which may be attributed to condensation caused by the relatively higher river temperature and near-freezing atmosphere temperature in autumn.

The monthly average sensible heat flux had a maximum heat gain of $20.88 \mathrm{~W} / \mathrm{m}^{2}$ in April and a maximum heat loss of $17.44 \mathrm{~W} / \mathrm{m}^{2}$ in September. The minimum heat exchange by sensible heat occurred in June $\left(5.62 \mathrm{~W} / \mathrm{m}^{2}\right)$. The mean daily energy exchange owing to sensible heat transfer was relatively small, accounting on average for less than 2.5 and $5.8 \%$ of the total heat gains and losses, respectively (Table 2). The sensible heat fluxes were generally lower in summer than in spring and autumn and mainly negative (Figure 9), which is attributed to the frequent fluctuations in the daily average temperature differences between the atmosphere and the river (Table 1). Although the maximum atmospheric temperature was higher than the river temperature, their daily average difference was relatively small. Except for heat losses in autumn, the thermal effect (cooling or heating) of the river on the atmosphere as sensible heat was not obvious during the observations.

The conductive heat flux indicated that the river heat gain or loss ranged between $-311.79 \mathrm{~W} / \mathrm{m}^{2}$ on April 10 and $332.38 \mathrm{~W} / \mathrm{m}^{2}$ on May 2 (Figure 9(a)). The monthly averages showed that the conductive heat flux was the second largest contributor to the heat loss in spring $(26.25 \%)$ and the largest to the heat gain $(39.07 \%)$ in autumn (Table 2), explaining the river temperature rise in spring and decrease in autumn (Figure 3(a)). In summer, both negative and positive components were small, according to the comparatively stable trend of the river temperature in Figure 3(a), meaning that the summer river heat budget was at equilibrium.

In general, all heat budget components were large in spring, gradually decreasing until autumn. The heat exchange in April was almost twofold that of June and fourfold that of
August. The minimum heat exchange occurred in October, representing one-sixth of the heat exchange in April. Large heat exchange fluxes between the atmosphere and the river occurred in spring, rising the river temperature. In summer, the heat exchange gradually decreased and was relatively stable, so that its intensity was small. In autumn, the heat exchange had an opposite direction and although its intensity was smaller than in summer, the opposite direction resulted in a river temperature decrease.

\section{Conclusions}

In this paper, various models were used to discuss the thermal relationship between the atmosphere and a large river by analyzing the temperatures and heat budget components of long-term observation data from Harbin, China, a city under severe cold continental climate conditions. In terms of microclimate variables, the atmosphere characteristics showed an overall higher variability than the river, with much larger differences between maximums and minimums for the study period. However, some features were shared, such as highly seasonally dependent temperature trends and relatively fluctuant conditions in spring and autumn and stable conditions in summer. The logistic regression fitted the weekly data better than the linear regression, while the stochastic model was more suitable to analyze daily maximum temperature relationships between the atmosphere and river. The difference between observed and modeled values was comparatively smaller in summer.

The heat budget components for the atmosphere-river interface varied widely in magnitude and significance, depending on the characteristics of the river and weather conditions. The net shortwave radiation flux was the dominant component of the heat gain, while the latent heat flux accounted for the main heat loss. The sensible heat flux had the smallest contribution to the total heat exchange. 
Significant seasonal differences in the absolute and relative magnitudes of the heat budget components affected the energy fluxes to and from rivers. All heat budget components were larger in spring, gradually decreasing until autumn. Large heat exchange fluxes between the atmosphere and river occurred in spring, leading to a temperature rise of the river. In summer, the heat exchange was relatively stable, with the main river thermal effect in the form of moisture diffusion. The heat exchange in autumn showed an opposite direction, resulting in a river heating effect on the atmosphere. Considering the relatively dry and hot summer conditions in Harbin, this thermal effect can effectively milden the adjacent thermal environment. The greatest contribution of the river for thermal mitigation was the absorption of solar radiation without a large temperature rise. The stable river conditions compensated for the relatively unstable atmospheric conditions, meaning that artificial underlying surfaces will aggravate the UHI problem as they are much more unstable than the atmosphere.

\section{Conflict of Interests}

The authors declare that there is no conflict of interests regarding the publication of this paper.

\section{Acknowledgments}

This study was supported by the National Natural Science Foundation of China (51438005) and the State Key Laboratory of Urban Water Resource and Environment (2010TS04). Additionally, the authors would like to thank Mr. Zhao Huiying from the Meteorological Science Institute in the Heilongjiang Province and Mr. Zhao Yu and Dr. Guo Liang for their assistance.

\section{References}

[1] J. J. Feddema, K. W. Oleson, G. B. Bonan et al., "The importance of land-cover change in simulating future climates," Science, vol. 310, no. 5754, pp. 1674-1678, 2005.

[2] G. B. Bonan, "Forests and climate change: forcings, feedbacks, and the climate benefits of forests," Science, vol. 320, no. 5882, pp. 1444-1449, 2008.

[3] L. Klok, S. Zwart, H. Verhagen, and E. Mauri, “The surface heat island of Rotterdam and its relationship with urban surface characteristics," Resources, Conservation and Recycling, vol. 64, no. 7, pp. 23-29, 2012.

[4] E. A. Hathway and S. Sharples, "The interaction of rivers and urban form in mitigating the Urban Heat Island effect: a UK case study," Building and Environment, vol. 58, pp. 14-22, 2012.

[5] S. Murakawa, T. Sekine, K.-I. Narita, and D. Nishina, "Study of the effects of a river on the thermal environment in an urban area," Energy and Buildings, vol. 16, no. 3-4, pp. 993-1001, 1991.

[6] B. Nagarajan, M. K. Yau, and P. H. Schuepp, "The effects of small water bodies on the atmospheric heat and water budgets over the Mackenzie River Basin," Hydrological Processes, vol. 18, no. 5, pp. 913-938, 2004.

[7] Y.-H. Kim, S.-B. Ryoo, J.-J. Baik, I.-S. Park, H.-J. Koo, and J.C. Nam, "Does the restoration of an inner-city stream in Seoul affect local thermal environment?" Theoretical and Applied Climatology, vol. 92, no. 3-4, pp. 239-248, 2008.
[8] Y.-C. Chen, C.-H. Tan, C. Wei, and Z.-W. Su, "Cooling effect of rivers on metropolitan Taipei using remote sensing," International Journal of Environmental Research and Public Health, vol. 11, no. 2, pp. 1195-1210, 2014.

[9] H. G. Stefan and E. B. Preud'Homme, "Stream temperature estimation from air temperature," Water Resources Bulletin, vol. 29, no. 1, pp. 27-45, 1993.

[10] B. W. Webb and F. Nobilis, "Long-term perspective on the nature of the air-water temperature relationship: a case study," Hydrological Processes, vol. 11, no. 2, pp. 137-147, 1997.

[11] T. R. Erickson and H. G. Stefan, "Linear air/water temperature correlations for streams during open water periods," Journal of Hydrologic Engineering, vol. 5, no. 3, pp. 317-322, 2000.

[12] B. W. Webb, P. D. Clack, and D. E. Walling, "Water-air temperature relationships in a Devon River system and the role of flow," Hydrological Processes, vol. 17, no. 15, pp. 3069-3084, 2003.

[13] O. Mohseni, H. G. Stefan, and T. R. Erickson, "A nonlinear regression model for weekly stream temperatures," Water Resources Research, vol. 34, no. 10, pp. 2685-2692, 1998.

[14] R. Grbić, D. Kurtagić, and D. Slišković, "Stream water temperature prediction based on Gaussian process regression," Expert Systems with Applications, vol. 40, no. 18, pp. 7407-7414, 2013.

[15] D. Caissie, N. El-Jabi, and A. St-Hilaire, "Stochastic modelling of water temperatures in a small stream using air to water relations," Canadian Journal of Civil Engineering, vol. 25, no. 2, pp. 250-260, 1998.

[16] D. Caissie, N. El-Jabi, and M. G. Satish, "Modelling of maximum daily water temperatures in a small stream using air temperatures," Journal of Hydrology, vol. 251, no. 1-2, pp. 14-28, 2001.

[17] V. Kothandaraman, "Analysis of water temperature variations in large river," Journal of the Sanitary Engineering Division, vol. 97, no. 1, pp. 19-31, 1971.

[18] D. Cluis, "Relationship between stream water temperature and ambient air temperature-a simple autoregressive model for mean daily stream water temperature fluctuations," Nordic Hydrology, vol. 3, no. 2, pp. 65-71, 1972.

[19] B. W. Webb and Y. Zhang, "Spatial and seasonal variability in the components of the river heat budget," Hydrological Processes, vol. 11, no. 1, pp. 79-101, 1997.

[20] J. M. Raphael, "Prediction of temperature in rivers and reservoirs," Journal of the Power Division, vol. 88, pp. 157-181, 1962.

[21] B. A. Sinokrot and H. G. Stefan, "Stream water-temperature sensitivity to weather and bed parameters," Journal of Hydraulic Engineering, vol. 120, no. 6, pp. 722-736, 1994.

[22] J. D. Lenters, T. K. Kratz, and C. J. Bowser, "Effects of climate variability on lake evaporation: results from a long-term energy budget study of Sparkling Lake, northern Wisconsin (USA)," Journal of Hydrology, vol. 308, no. 1-4, pp. 168-195, 2005.

[23] S. K. Gianniou and V. Z. Antonopoulos, "Evaporation and energy budget in Lake Vegoritis, Greece," Journal of Hydrology, vol. 345, no. 3-4, pp. 212-223, 2007.

[24] K. Momii and Y. Ito, "Heat budget estimates for Lake Ikeda, Japan," Journal of Hydrology, vol. 361, no. 3-4, pp. 362-370, 2008.

[25] B. Ahmadi-Nedushan, A. St.-Hilaire, T. B. M. J. Ouarda et al., "Predicting river water temperatures using stochastic models: case study of the Moisie River (Québec, Canada)," Hydrological Processes, vol. 21, no. 1, pp. 21-34, 2007.

[26] L. Benyahya, D. Caissie, N. El-Jabi, and M. G. Satish, "Comparison of microclimate vs. remote meteorological data and results applied to a water temperature model (Miramichi River, Canada)," Journal of Hydrology, vol. 380, no. 3-4, pp. 247-259, 2010. 
[27] X. C. Song, J. Liu, and L. Guo, "Field measurement of the large urban river effect on urban thermal climate," in Proceedings of the International Conference on Computer Distributed Control and Intelligent Environmental Monitoring, pp. 71-74, IEEE Computer Society, Hunan, China, 2011.

[28] G. Han, H. Chen, L. Yuan, Y. Cai, and M. Han, "Field measurements on micro-climate and cooling effect of river wind on urban blocks in Wuhan city," in Proceedings of the 2nd International Conference on Multimedia Technology (ICMT '11), pp. 4446-4449, IEEE, Hangzhou, China, July 2011.

[29] C. E. Torgersen, R. N. Faux, B. A. McIntosh, N. J. Poage, and D. J. Norton, "Airborne thermal remote sensing for water temperature assessment in rivers and streams," Remote Sensing of Environment, vol. 76, no. 3, pp. 386-398, 2001.

[30] W. H. Brutsaert, Evaporation Into the Atmosphere: Theory, History and Applications, D. Reidel Publishing Company, Dordrecht, The Netherlands, 1982.

[31] D. O. Rosenberry, T. C. Winter, D. C. Buso, and G. E. Likens, "Comparison of 15 evaporation methods applied to a small mountain lake in the northeastern USA," Journal of Hydrology, vol. 340, no. 3-4, pp. 149-166, 2007.

[32] J. Jaworski, "Effects of heated water discharge on the evaporation from a river surface," Journal of Hydrology, vol. 19, no. 2, pp. 145-155, 1973.

[33] G. E. J. Harbeck, M. A. Kohler, and G. E. Koberg, "Water-loss investigations: lake mead studies," US Geological Survey Professional Paper 298, 1958.

[34] R. B. Stewart and W. R. Rouse, "A simple method for determining the evaporation from shallow lakes and ponds," Water Resources Research, vol. 12, no. 4, pp. 623-628, 1976.

[35] A. H. Rasmussen, M. Hondzo, and H. G. Stefan, "A test of several evaporation equations for water temperature simulations in lakes," Water Resources Bulletin, vol. 31, no. 6, pp. 1023-1028, 1995.

[36] P. H. M. Janssen and P. S. C. Heuberger, "Calibration of processoriented models," Ecological Modelling, vol. 83, no. 1-2, pp. 5566, 1995. 

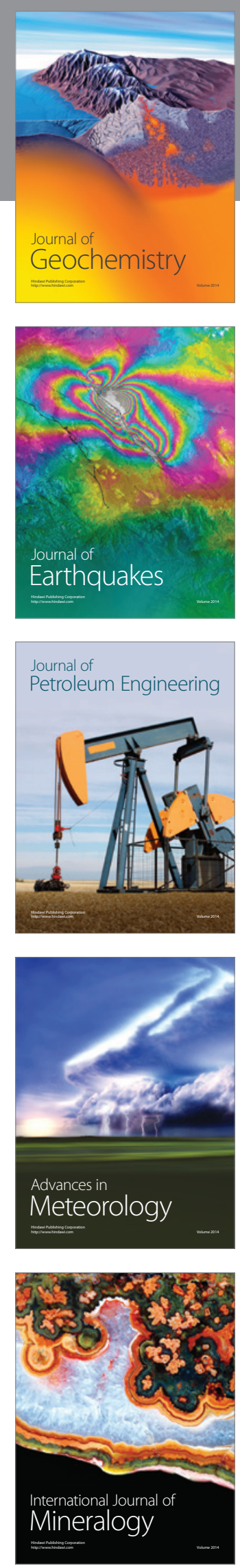
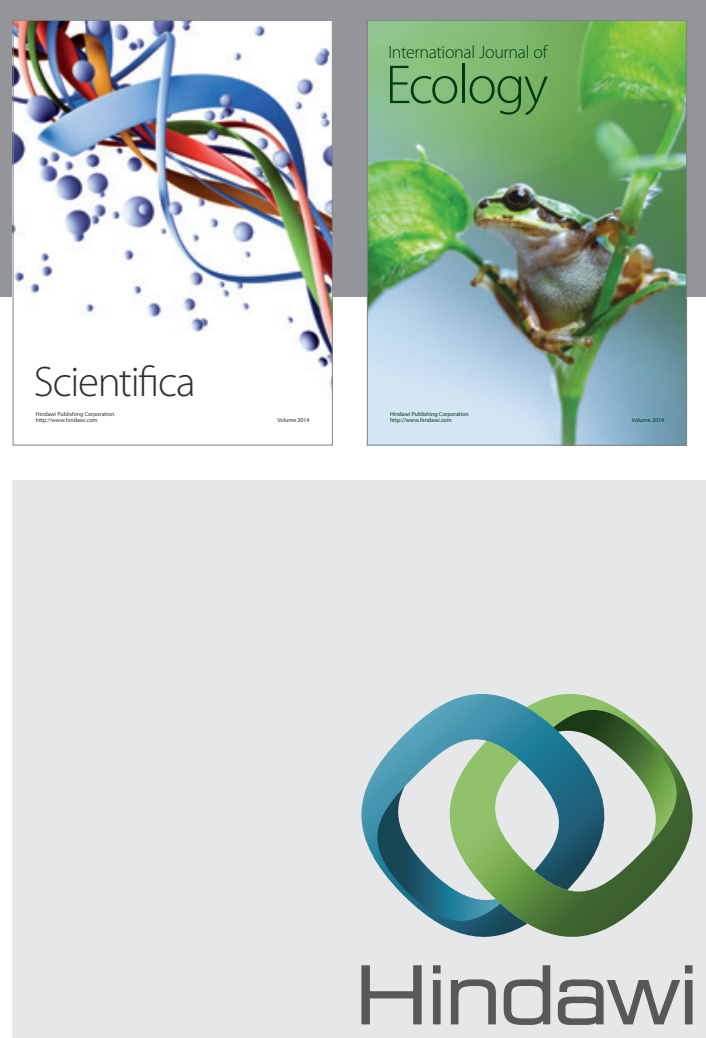

Submit your manuscripts at

http://www.hindawi.com
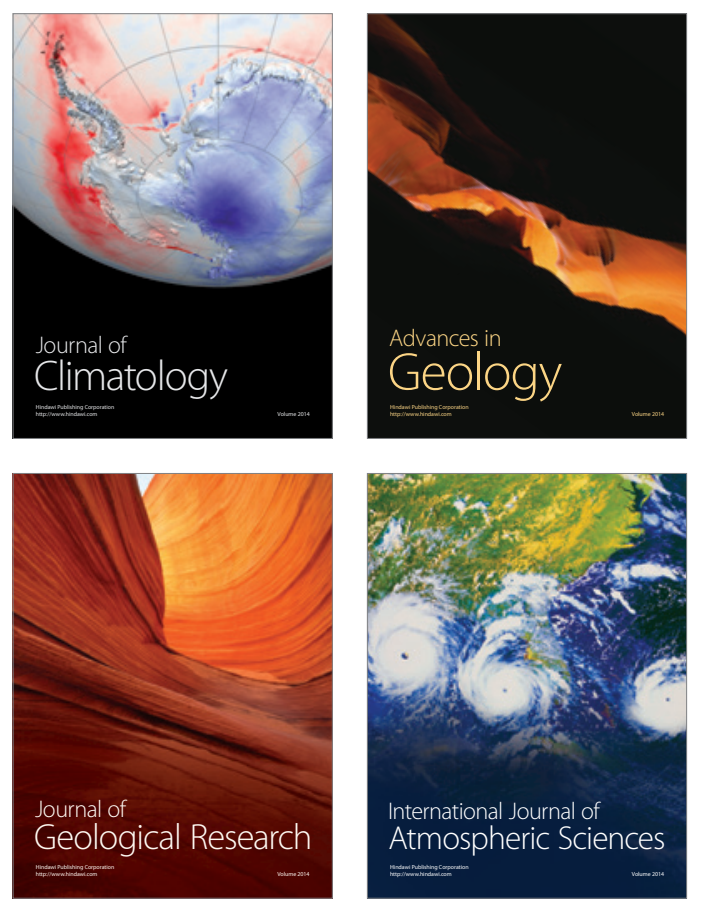

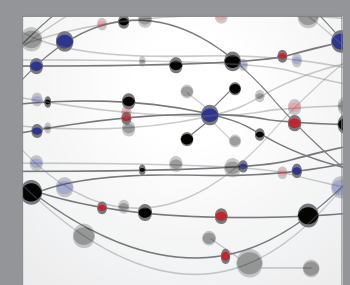

The Scientific

\section{World Journal}
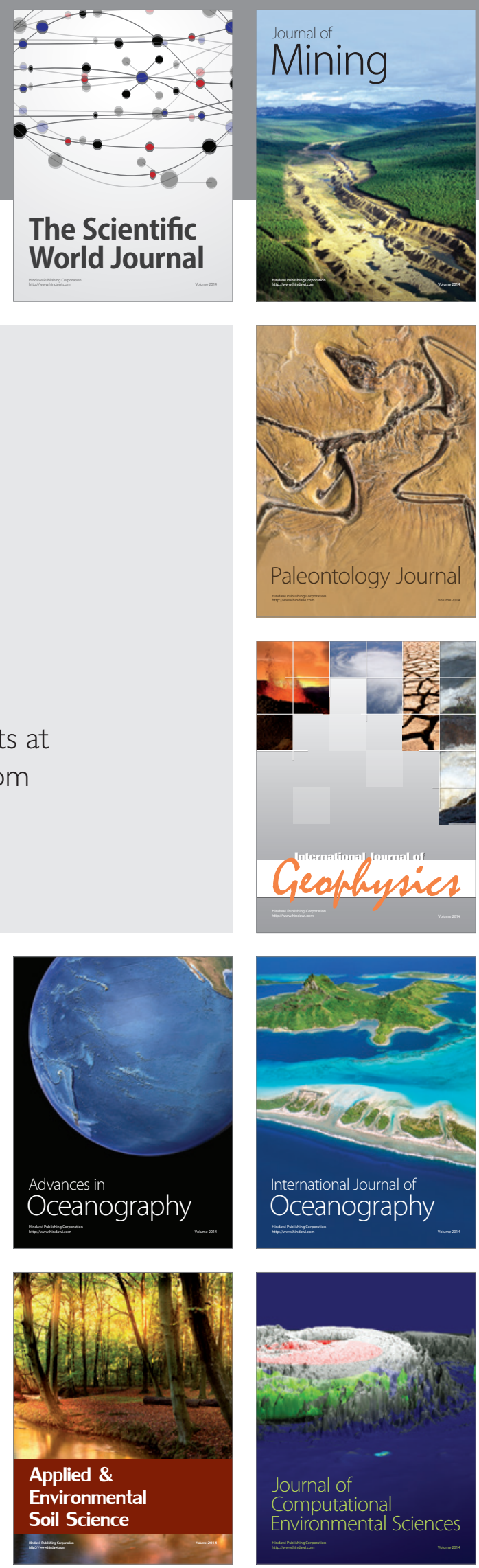